\title{
Genetic Characterization of Six Stocks of Litopenaeus vannamei Used in Cuba for Aquaculture by Means of Microsatellite Loci
}

\author{
Anna Pérez-Beloborodova, ${ }^{1}$ Adriana Artiles-Valor, ${ }^{2}$ Lourdes Pérez-Jar, ${ }^{2}$ \\ Damir Hernández-Martínez, ${ }^{1}$ Missael Guerra-Aznay, ${ }^{2}$ and Georgina Espinosa-López ${ }^{3}$ \\ ${ }^{1}$ Conservation Genetic Group, Marine Research Centre, University of Havana, Street 16 No 114, Playa Havana, CP 11300, Cuba \\ ${ }^{2}$ Molecular Biology Laboratory, Aquaculture Division, Fisheries Research Centre, 5th Avenue and 246, \\ Barlovento, Playa, Havana, CP 19100, Cuba \\ ${ }^{3}$ Department of Biochemistry, Faculty of Biology, Havana University, Street 25 No. 455 between J. and I. Vedado, Havana, Cuba
}

Correspondence should be addressed to Georgina Espinosa-López, georgina@fbio.uh.cu

Received 30 August 2011; Revised 1 November 2011; Accepted 11 November 2011

Academic Editor: Pung-Pung Hwang

Copyright (C 2012 Anna Pérez-Beloborodova et al. This is an open access article distributed under the Creative Commons Attribution License, which permits unrestricted use, distribution, and reproduction in any medium, provided the original work is properly cited.

\begin{abstract}
Four microsatellite loci were used to achieve genetic characterization of six stocks from Litopenaeus vannamei used for aquaculture in Cuba: second generation from first introduction (S2-1), first generation from the second one (S1-2), from the third one (S1-3), and the fourth one (S1-4) and the crossings from two parental population: first generation from the first with first generation from the third (S1-1 $\times$ S1-3) and first generation from the second with first generation from the third (S1-2 $\times$ S1-3). 66\% (16/24) of genetic systems in total loci were in genetic disequilibrium. The four microsatellite loci were polymorphic for all six stocks. Major quantities of allelic variants correspond to locus Pvan 1758, which is at the same time that one where there are private alleles from first generation of the third. All Fst comparisons were significant. This indicates big differences between stocks. The highest values are those in which there is presence of the second introduction. This introduction and its descendants are also more consanguineous.
\end{abstract}

\section{Introduction}

In Latin America shrimp-producer countries, the Pacific white shrimp, Litopenaeus vannamei, is the most representative species, with about $90 \%$ of production. Native from East Pacific, and from the tropical American continent, this species has shown an excellent culture adaptation and has been more resistant to salinity, oxygen, and temperature fluctuations. That is why, in the last twenty years, Litopenaeus vannamei, has been introduced in many culture programs, and nowadays it is the second culture after Penaeus monodon.

In 2003 the first introduction of two stocks of White Pacific Shrimp, Litopenaeus vannamei, [1] was achieved in Cuba, imported from USA, Shrimp Improving System and so handling, nutrition, and health techniques are well established, as well as the assessment of genetic variation in farms that had before cultured the indigenous species Litopenaeus schmitti. In total, five stocks have been introduced, and all of them have been characterized using microsatellite techniques [2-4].

Genetic studies have a capital importance in shrimp industry, in order to determine genetic variability level either in natural or cultured populations, but mainly to know when the latter could be enriched with new specimens [5]. It is moreover important to know the structure of natural population from which those specimens will be taken [6] and also to have good markers that allow population and family studies. It is clear that the priority should be given to the domestication and handling of broodstocks through the application of genetic techniques [7-9]. The aim of the present work is to characterize different cultured stocks of Litopenaeus vannamei, used in Cuba for aquaculture, by means of microsatellite markers. 


\section{Materials and Methods}

2.1. Samples. Samples were taken from pleopods of 30 shrimps, specifically from the fourth pair, between exo-and endopodite. The same male and female quantity was taken randomly in shrimps from the Postlarvae Production Hatchery "YAGUACAM," Cienfuegos, Cuba.

Individuals from first or second generation of introduced shrimps were taken for this genetic characterization as described below. Two first parental generations from first and second introduced stocks were randomly crossed with descendants of the first generation of the third introduced stock resulting in (S1-2 $\times \mathrm{S} 1-3)$ and $(\mathrm{S} 1-1 \times \mathrm{S} 1-3)$ as it is called in this work.

Thus, characterized lots were second generation from first introduced stock (S2-1), first generation from the second one (S1-2), from the third one (S1-3), and from the fourth one (S1-4) and the crossings: first generation from the first with first generation from the third (S1-1 $\times$ S1-3) and first generation from the second with first generation from the third $(\mathrm{S} 1-2 \times \mathrm{S} 1-3)$.

2.2. Microsatellite Genotyping. DNA isolation, amplification programs, and electrophoresis procedures were carried out as described in [2]. Used loci were $M-1$, isolated from $L$. vannamei by [10] and Pvan 0040, Pvan 1758, and Pvan 1815 obtained from the same species by [11]. As weight allelic controls, samples previously genotyped by [2], as well as PGEM, were used.

2.3. Statistics. Allele number by locus, allele frequency, and observed and expected heterozygosity for each locus, as well as, the Hardy-Weinberg equilibrium, were determined by GeneAlEx 6.1 program [12]. A locus was considered as polymorphic if it presented at least two alleles and when the most common frequency of an allele did not exceed 95\%.

The FSTAT statistical package version 2.93 [13] was used to calculate the linkage disequilibrium, and also the inbreeding coefficient within populations, $F_{\text {is }}$ values [14], and pairwise $F_{\text {st }}$ and $P$ values between populations, after 1500 permutations. Significance levels were assessed through the Markov chains using 10000 Dememorisation, 100 batches, and 5000 iterations per batch using the Genepop Version 4.1.0 [15].

Assignment tests were used to clarify the belonging of individuals to the stocks. The Bayesian assignment test was performed [16] among shrimp stocks from Cuba using GeneClass 2 [17]. Simulations were run to determine the probability of assignment, using a probability of rejection set at $P<0.05$.

Relatedness coefficient $(r)$ according to [18] between individuals' pairs was calculated by GeneAlEx 6.1 program [12]. The equation for this coefficient taking into consideration codominant marker is

$$
r=\frac{\sum_{x} \sum_{k} \sum_{l}\left(p_{y}-p^{*}\right)}{\sum_{x} \sum_{k} \sum_{l}\left(p_{x}-p^{*}\right)}
$$

where $x$ represents individuals, $k$ all loci, $l$ allelic positions ( 2 for diploids, 1 for haploids), $P_{x}$ the frequency of the individual $x$ for the locus $k$ and allelic position $1, P_{y}$ the frequency of the allele in the group or individual with it is compared $x$, and $P^{*}$ the total frequency in the population.

Relatedness coefficient must be $r \leq 0$ to unrelated individuals, $r=0.25$ to half sibs, and $r \geq 0.5$ to full sibs [18].

Relatedness means coefficients were compared with the Kruskal Wallis test (nonparametric ANOVA) by means of graphPad InStat version 3.00 [19]

\section{Results}

3.1. General Parameters of Genetic Variation of Six Stocks Descendants from Original Introductions: Hardy-Weinberg Deviation of Equilibrium. As it has been previously reported, L. vannamei shrimps introduced from SIS are characterized [2-4].

In the present work, the genetic variation analysis was performed to six relative stocks of those introductions by means of four microsatellite loci: M1, isolated from $L$. vannamei, and Pvan 0040, Pvan 1758, and Pvan 1815 also obtained from these species. Linkage disequilibrium was analyzed, and as it is known $[2,4,11,20]$, those loci for $L$. vannamei are not linked.

In Table 1 are shown the main genetic estimation parameters, such as number of alleles (Na) and number of effective alleles $(\mathrm{Ne}$ ), observed and expected heterozigocities (Ho and $\mathrm{He}$ ), and so, the Hardy-Weinberg equilibrium deviations ( $\mathrm{F}_{\mathrm{IS}}$ values). As several stocks are compared, private alleles are also provided $(\mathrm{Np})$. Note that first generation from second introduction $(\mathrm{S} 1-2)$ is the one of less genetic variability, within first generation stocks, and even lesser than the only second generation stock analyzed. Highest variation stock belongs to crossing of first generation from the first with first generation from the third $(\mathrm{S} 1-1 \times \mathrm{S} 1-3)$. The lowest relative variation of any generations and stocks which included second introduction is remarkable and stocks which included second introduction.

Normally, the Hardy-Weinberg equilibrium conditions are not accomplished in cultures. In Table 1 it is observed that $66 \%(16 / 24)$ of genetic systems in total loci are significant in genetic disequilibrium by homozygotes excess.

3.2. Differentiation between Stocks. In Figure 1 frequencies of alleles of each microsatellite for all stocks are shown. Allele sizes are on range reported by other authors [2-4, 10, 2022]. All loci were polymorphic and those with more allelic variants were Pvan 1758 (12 variants) and Pvan 1815 (9 variants), which is coincident with previous studies. Private alleles found in this paper corresponded to those loci. In the case of M1, distribution of frequencies is bimodal, with two predominant sizes, which includes the majority of stocks: 216, which contains all of them, and 202 in which it only lacks S1-4. In total there are eight allelic variants, and there are not private alleles for this microsatellite region. 
TABle 1: Genetic variability parameters and the Hardy-Weinberg deviation of equilibrium $\left(F_{I S}\right)$ and its probability (Pfis) of four microsatellites loci isolated from L. vannamei, M-1 [10], Pvan 0040, Pvan 1758 and Pvan 1815 [11], in six different cultured stocks of L. vannamei used for aquaculture in Cuba. $n$ : number of samples. Na: number of alleles, Ne: number of effective alleles, Np: number of private alleles, He: expected heterozygosity, Ho: observed heterozygosity. The associated probability was estimated using the Markov chains (10000 Dememorisation, 100 batches, and 5000 iterations per batch using Genepop program Version 4.1.0. Numbers in parenthesis are standard mean error.

\begin{tabular}{|c|c|c|c|c|c|c|c|c|}
\hline Stock & $\mathrm{N}$ & $\mathrm{Na}$ & $\mathrm{Ne}$ & $\mathrm{Np}$ & Ho & $\mathrm{He}$ & Fis & Pfis \\
\hline \multicolumn{9}{|c|}{ Locus M1 } \\
\hline S2-1 & 19 & 7 & 4.6 & 0 & 0.89 & 0.78 & -0.115 & 0.001 \\
\hline S1-2 & 19 & 4 & 2.2 & 0 & 0.62 & 0.55 & -2.212 & 0.660 \\
\hline S1-3 & 16 & 5 & 3.6 & 0 & 0.69 & 0.72 & 0.078 & 0.000 \\
\hline S1-4 & 22 & 3 & 2.0 & 0 & 0.59 & 0.50 & -0.147 & 0.142 \\
\hline $\mathrm{S} 1-1 \times \mathrm{S} 1-3$ & 23 & 5 & 3.0 & 0 & 0.91 & 0.67 & -0.349 & 0.242 \\
\hline $\mathrm{S} 1-2 \times \mathrm{S} 1-3$ & 25 & 4 & 3.1 & 0 & 0.36 & 0.68 & 0.485 & 0.000 \\
\hline \multicolumn{9}{|c|}{ Locus Pvan 0040} \\
\hline S2-1 & 21 & 4 & 2.4 & 0 & 0.52 & 0.58 & 0.127 & 0.002 \\
\hline S1-2 & 21 & 2 & 1.3 & 0 & 0.24 & 0.21 & -0.111 & 1.000 \\
\hline S1-3 & 19 & 4 & 2.5 & 0 & 0.16 & 0.59 & 0.746 & 0.000 \\
\hline $\mathrm{S} 1-4$ & 22 & 3 & 2.7 & 0 & 0.36 & 0.63 & 0.440 & 0.000 \\
\hline $\mathrm{S} 1-1 \times \mathrm{S} 1-3$ & 23 & 4 & 3.9 & 0 & 0.56 & 0.74 & 0.261 & 0.000 \\
\hline $\mathrm{S} 1-2 \times \mathrm{S} 1-3$ & 26 & 2 & 1.3 & 0 & 0.23 & 0.20 & -0.111 & 1.000 \\
\hline \multicolumn{9}{|c|}{ Locus 1758} \\
\hline$\overline{S 2-1}$ & 21 & 7 & 3.8 & 0 & 0.67 & 0.54 & 0.121 & 0.00 \\
\hline S1-2 & 21 & 4 & 3.5 & 0 & 0.67 & 0.71 & 0.088 & 0.000 \\
\hline S1-3 & 20 & 9 & 6.2 & 3 & 0.75 & 0.84 & 0.132 & 0.054 \\
\hline S1-4 & 22 & 7 & 3.9 & 1 & 0.68 & 0.74 & 0.108 & 0.009 \\
\hline $\mathrm{S} 1-1 \times \mathrm{S} 1-3$ & 23 & 6 & 4.5 & 0 & 0.61 & 0.78 & 0.239 & 0.119 \\
\hline $\mathrm{S} 1-2 \times \mathrm{S} 1-3$ & 26 & 6 & 1.8 & 0 & 0.73 & 0.64 & -0.116 & 0.563 \\
\hline \multicolumn{9}{|c|}{ Locus 1815} \\
\hline S2-1 & 21 & 3 & 2.1 & 0 & 0.14 & 0.52 & 0.737 & 0.00 \\
\hline S1-2 & 21 & 4 & 1.6 & 0 & 0.25 & 0.37 & 0.371 & 0.056 \\
\hline S1-3 & 20 & 6 & 3.8 & 0 & 0.65 & 0.74 & 0.147 & 0.006 \\
\hline S1-4 & 22 & 6 & 4.4 & 1 & 0.73 & 0.77 & 0.084 & 0.000 \\
\hline $\mathrm{S} 1-1 \times \mathrm{S} 1-3$ & 23 & 8 & 3.8 & 0 & 0.52 & 0.74 & 0.315 & 0.000 \\
\hline $\mathrm{S} 1-2 \times \mathrm{S} 1-3$ & 26 & 4 & 3.6 & 0 & 0.65 & 0.72 & 0.115 & 0.000 \\
\hline \multicolumn{9}{|c|}{ All loci } \\
\hline S2-1 & $20.5(0.5)$ & $5.2(1.0)$ & $3.2(0.6)$ & 0 & $0.56(0.16)$ & $0.66(0.06)$ & 0.176 & 0.000 \\
\hline S1-2 & $20.5(0.5)$ & $3.5(0.5)$ & $2.1(0.5)$ & 0 & $0.46(0.13)$ & $0.46(0.11)$ & 0.032 & 0.000 \\
\hline S1-3 & $18.7(0.9)$ & $6.0(1.0)$ & $4.0(0.8)$ & 3 & $0.56(0.14)$ & $0.72(0.05)$ & 0.250 & 0.000 \\
\hline S1-4 & $22.0(0.0)$ & $4.7(1.0)$ & $3.3(0.5)$ & 2 & $0.59(0.08)$ & $0.66(0.06)$ & 0.132 & 0.000 \\
\hline $\mathrm{S} 1-1 \times \mathrm{S} 1-3$ & $23.0(0.0)$ & $5.0(0.8)$ & $3.8(0.3)$ & 0 & $0.65(0.90)$ & $0.73(0.02)$ & 0.131 & 0.000 \\
\hline $\mathrm{S} 1-2 \times \mathrm{S} 1-3$ & $25.7(0.2)$ & $4.0(0.8)$ & $2.7(0.5)$ & 0 & $0.50(0.12)$ & $0.56(0.12)$ & 0.141 & 0.000 \\
\hline
\end{tabular}

Pvan 0040 locus is that one which has less allelic variants, with only five. Its frequency distribution is unimodal and in 141 size all stocks are represented. Two other loci, Pvan 1758 and Pvan 1815, are unimodal and have private alleles that contribute to the highest quantity of allelic variants. Private alleles correspond to the first generations of the third and fourth introductions. Sizes and frequencies of appeared alleles (within parenthesis) are, for locus 1758: 182 (0.025), $184(0.250)$, and $193(0.025)$, which appeared in first generation of the third and $210(0.023)$ from first generation of the 4 th. To 1815 there is only a private allele from first generation of the 4th: 111 (0.091).

The assignment test results are represented in Table 2. It revealed that $93.3 \%(125 / 134)$ from the shrimp were correctly assigned. S1-3 stock was the most failed assignation with only $80 \%$ of right assignation.

$F_{\text {st }}$ calculations are shown on Table 3 , comparing all stocks among them. It is observed that all comparisons are statistically significant. The biggest values are those that have the presence of the second introduction. On the other hand, 


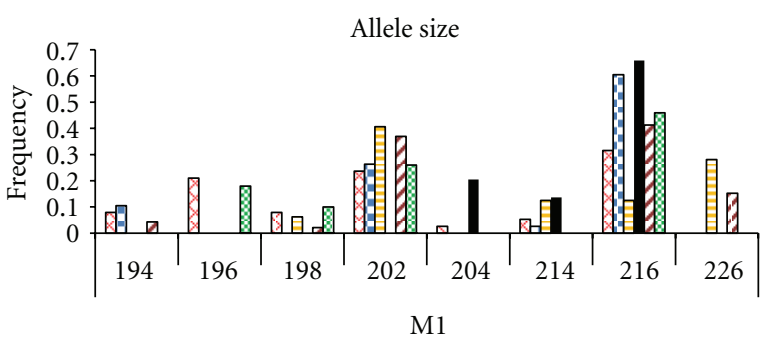

(a)

Allele size

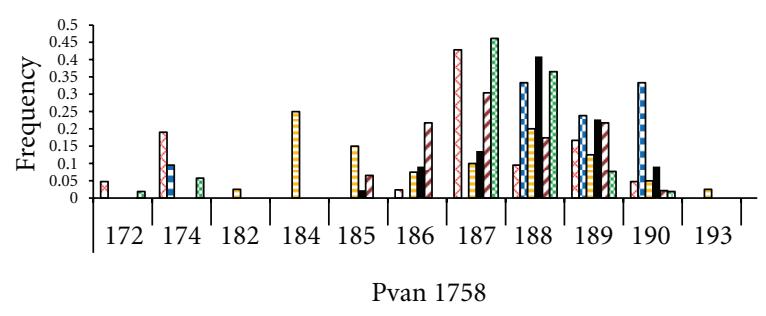

$\otimes S 2-1$
$\square S 1-2$
$\square S 1-3$

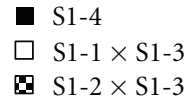

(c)

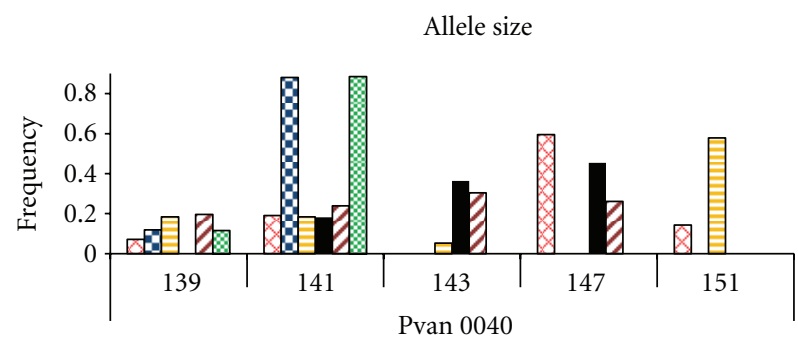

(b)

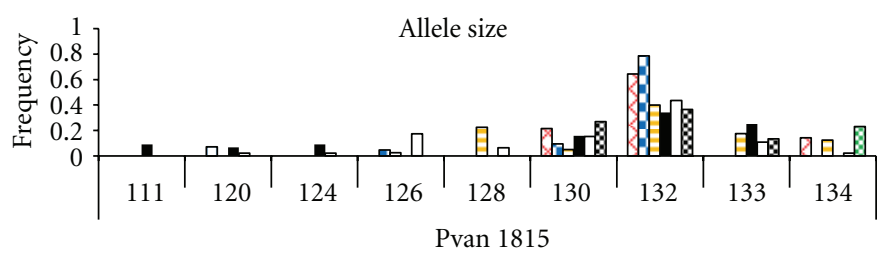

- $\mathrm{S} 1-4$

$\square \mathrm{S} 1-1 \times \mathrm{S} 1-3$

S $1-2 \times \mathrm{S} 1-3$

(d)

Figure 1: Allelic frequencies of loci M-1 [11], Pvan 0040, Pvan 1758 and, Pvan 1815 [12] for six L. vannamei stocks used for aquaculture in Cuba.

TABLE 2: Number of assigned individuals to the correspondent stock and/or to any other using the Bayesian assignment test [16] by GeneClass [17]. Simulations were run to determine the probability of assignment, using a probability of rejection set at $P<0.05$.

\begin{tabular}{lccc}
\hline Stock & $\begin{array}{c}\text { Assigned to the } \\
\text { same stock }\end{array}$ & $\begin{array}{c}\text { Assigned to } \\
\text { another stock }\end{array}$ & $\begin{array}{c}\text { \% of assignment to } \\
\text { the same stock }\end{array}$ \\
\hline S2-1 & 19 & 2 & 90,50 \\
S1-2 & 20 & 1 & 95,5 \\
S1-3 & 16 & 4 & 80 \\
S1-4 & 21 & 1 & 95,4 \\
S1-1 $\times$ S1-3 & 23 & 0 & 100 \\
S1-2 $\times$ S1-3 & 26 & 1 & 96 \\
\hline Total & 125 & 9 & 93.2 \\
\hline
\end{tabular}

less $F_{\text {st }}$ values are observed in comparisons between S1-3, S14 , and S2-1.

3.3. Relatedness Values. Relatedness coefficients distributions between individual pairs of six stocks are shown in Figure 2, calculated according to [18]. All stocks, except S1-2 and crossing that contains it (S1-2 $\times$ S1-3), present unimodal distributions. Three of them present the mode in negative relatedness values $(\mathrm{S} 1-3, \mathrm{~S} 1-4, \mathrm{~S} 1-1 \times \mathrm{S} 1-3)$, and the only one from a second generation $\mathrm{S} 2-1$ presents the mode in zero. In the case of exceptions, for S1-2, one of the modes is near zero, while the second one is near positive values but
TABLE 3: $F_{s t}$ values estimated by FSTAT program [13] between L. vannamei shrimp stocks used for culture in Cuba. For all comparisons, $P$ value $=0.00067$; it was obtained after 1500 permutations also by the FSTAT program. Indicative adjusted nominal level (5\%) for multiple comparisons is 0.003333 .

\begin{tabular}{lccccc}
\hline & S2-1 & S1-2 & S1-3 & S1-4 & S1-1 $\times$ S1-3 \\
\hline S1-2 & 0.2163 & & & & \\
S1-3 & 0.1496 & 0.2387 & & & \\
S1-4 & 0.1192 & 0.2120 & 0.1896 & & \\
S1-1 × S1-3 & 0.0667 & 0.1637 & 0.0962 & 0.0663 & \\
S1-2 × S 1-3 & 0.1639 & 0.1237 & 0.2030 & 0.1922 & 0.1282 \\
\hline
\end{tabular}

lower than 0.5 . For crossing (S1-2 $\times \mathrm{S} 1-3)$, the first mode is in negative values and the other one near zero. Mean relatedness coefficients values (Figure 2, right inside) have not significant differences and have standard deviation values. Those are for each stock, S2-1: -0.028; S1-2: 0.044; S1-3: -0.063; S1-4: -0.023 ; S1-2 × S1-3: -0.019 ; S1-1 $\times$ S1-3: -0.044 .

\section{Discussion}

4.1. Genetic Diversity within L. vannamei Stocks. The four microsatellite loci were polymorphic for all six stocks. The majority of expected and observed heterozigocities are on range according to many authors using microsatellites for penaeid shrimps $[2-4,20-26]$. However, they are low and above range for one of the markers, Pvan 0040, which 


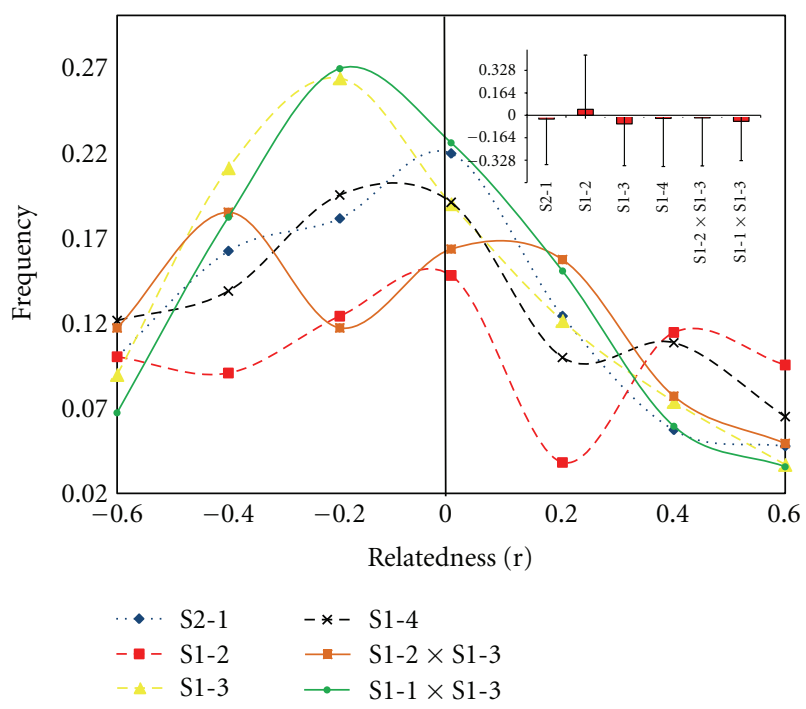

Figure 2: Relatedness coefficient distributions between individual pairs from stocks of L. vannamei shrimps used for culture in Cuba, calculated according to [18], with 4 microsattellite loci: M-1 [10], Pvan 0040, Pvan 1758, and Pvan 1815 [11]. Rigth inside: mean values and standard deviation of relatedness coefficients for all stocks. $P$ value for statistical comparison is 0.2426 .

is the less variable loci of all stocks in which the second introduction is involved: in the first generation of the second introduction $\mathrm{Ho}=0.24$ and $\mathrm{He}=0.21$ and in crossing of first generation of second introduction with first generation of the first. Previously, [2-4] reported a great contribution of this locus to the decrease of total heterozigocities. Pvan 0040 was monomorphic for the original fourth and fifth introductions [3, 4], and so it could be considered that this locus is sufficiently sensitive to changes in different stocks.

Equilibrium deviations are significant in most loci by stocks, which in accord with other authors' results $[3,4,20$, 22].

Most of allelic frequency graphics are unimodals, with exception of M1 locus. The biggest quantities of allelic variants correspond to locus Pvan 1758, which is at the same time that one in which there are private alleles from first generation of the third. This is in agreement with genetic variability reported for that locus in previous works [20,22, 25].

4.2. Differentiation between Stocks. Indeed all $F_{\text {st }}$ comparisons were significant. They indicate big differences between stocks. The biggest values are those in which there is presence of the second introduction. In a similar way, other authors also obtained significant differences in natural populations as well as in cultured stocks $[20,22]$. Using allozymes, the authors in $[27,28]$ also obtained a genetic differentiation in wild population of L. shmitti in Cuba and in wild and cultured L. vannamei stocks in Norwest Mexico, respectively. Those differences are in agreement with the assigning exercise, in which only first generation of the third stock had low percentages of assigning. It could be because there are components of those stocks in others obtained by meanings of crossing with this third introduction.

Although studies with L. vannamei in Cuba indicate a decrease in genetic variability, existing stocks at the moment of this genetic characterization, even with little variations, seem, however, significantly different between them. The reason could be that in their origins they constitute genetic lines well diverse in their origins in respect to the main objective for production (e.g., illness resistance, increasing growth, etc.). However, once the selection pressure is increased, genetic variation is decreased as it could be seen in different genetic variability reports for several introductions $[4,29]$.

4.3. Relatedness Coefficients. Borrell et al. [2] pointed out the risk that could implicate using individuals from the second introduced stock for crossing with others without any methodology such as the following, of relatedness coefficient, that offers information about inbreeding levels. For the second stock, they obtained a mean relatedness coefficient indicative of more related individuals than those of the first one, similar to the results of this work, in which the most consanguineous stock is descendants of this second introduced stock. The highest value, indicative of a great relatedness, was obtained for the fifth introduced stock of L. vannamei in Cuba [4], and that is why the use of this molecular tool is of crucial importance for designing and following crossings. The rest of the stocks show means and distributions in agreement with individuals presumed not related, similar to that obtained by [30] for turbot, near zero. The second introduction and its descendants, as well as crossings that contain it, the same as the fifth [4], should be followed with this methodology, and also estimation of heritability for interested characters for culture would be profitable.

4.4. General Remarks. A progressive decrease in genetic variability is observed in successive introductions of L. vannamei into Cuba since 2003 and henceforth. It means that the first broodstock should be maintained and combined with others or new stock. Relatedness coefficients support the use of this stock and highlight the fact that the second stock should be carefully used in crossings because of their tendency to positive values.

However, the sustainability of the culture has been achieved, as well as maintenance of no viral diseases that have caused considerable losses in Latin America [31]. In that way, if surveillance program [32], starts with the premise of introducing SPF animals (Shrimp Pathogens Free) for health maintenance in cultures, a strategy of genetic management with microsatellite markers will warranty an adequate productive performance that does not drive to an irreversible endogamy. In agreement with [2], the maintenance of a common origin, besides of health warranty ever crossing stocks genetically different, avoids phenomena as outbreeding depression [33-35] that could damage productive yields in a short time. 


\section{Acknowledgments}

Many thanks are due to workers and technicians from the Postlarvae Production Hatchery "YAGUACAM," in Cienfuegos, Cuba, for technical support in maintenance of lines, especially to its director, Ms. Angela Moreno. Special thanks are due to Dr. Vicente Berovides for his critical revision of the text and also to MSc. Román Machado for his comments. The authors also thank the anonymous referees for improving the document with their comments and remarks. They also want to express their gratitude to Ms. Mercedes Escobar for editing and improving English from the original manuscript.

\section{References}

[1] R. Tizol, B. Jaime, R. Laria et al., "Introduction of Pacific White Shrimp L. vannamei in Cuba. Quarantine I step (In Spanish). Ocean Docs," http://hdl.handle.net/1834/3588, 2004.

[2] Y. J. Borrell, G. Espinosa, E. Vazquez, J. A. Sánchez, and G. Blanco, "Genetic variability of microsatellite loci in the two first stocks of Litopenaeus vannamei introduced to Cuba for aquaculture," Revista de Investigaciones Marinas, vol. 27, no. 3, pp. 237-244, 2006 (Spanish).

[3] R. Machado, Assessment of genetic variability in two lots of white shrimp, Litopenaeus vannamei (Boone, 1931) introduced to Cuba, M.S. thesis, International Fisheries Management. Department of Aquatic Biosciences. Norwegian College of Fishery Science. University of Tronso, Norway, Oslo, 2006.

[4] A. Artiles, I. Rodríguez, A. Pérez, L. Pérez, and G. Espinosa, "Low genetic variability in the fifth introduction of Litopenaeus vannamei in Cuba, as estimated with microsatellite markers," Biotecnología Aplicada, vol. 28, pp. 142-146, 2011.

[5] D. K. García, M. A. Faggart, L. Rhoades et al., "Genetic diversity of cultured Penaeus vannamei shrimp using three molecular genetic techniques," Molecular Marine Biology and Biotechnology, vol. 3, no. 5, pp. 270-280, 1994.

[6] S. Sunden and K. Davis, "Evaluation of genetic variation in a domestic population of Penaeus vannamei (Boone): a comparison with three natural populations," Aquaculture, vol. 97, no. 2-3, pp. 131-142, 1991.

[7] R. A. Dunham, K. Majumdar, E. Hallerman et al., "Review of the status of aquaculture genetics," in Aquaculture in the Third Millennium. Technical Proceedings of the Conference on Aquaculture in the Third Millennium (February 2000, Bangkok, Thailand), R. P. Subasinghe, P. Bueno, M. J. Phillips, C. Hough, S. E. McGladdery, and J. R. Arthur, Eds., pp. 137-166, NACA/FAO, 2001.

[8] G. Hulata, "Genetic manipulations in aquaculture: a review of stock improvement by classical and modern technologies," Genetica, vol. 111, no. 1-3, pp. 155-173, 2001.

[9] Z. J. Liu and J. F. Cordes, "DNA marker technologies and their applications in aquaculture genetics," Aquaculture, vol. 238, no. 1-4, pp. 1-37, 2004.

[10] G. M. Wolfus, G. K. García, and A. Alcivar-Warren, "Application of the microsatellite technique for analyzing genetic diversity in shrimp breeding programs," Aquaculture, vol. 152, no. 1-4, pp. 35-47, 1997.

[11] P. Cruz, C. H. Mejía-Ruiz, R. Pérez-Enriquez, and A. M. Ibarra, "Isolation and characterization of microsatellites in Pacific white shrimp Penaeus (Litopenaeus) vannamei," Molecular Ecology Notes, vol. 2, no. 3, pp. 239-241, 2002.
[12] R. Peakall and P. E. Smouse, "GENALEX 6: genetic analysis in Excel. Population genetic software for teaching and research," Molecular Ecology Notes, vol. 6, no. 1, pp. 288-295, 2006.

[13] J. Goudet, "FSTAT, a program to estimate and test gene diversities and fixation indexes. (version 2.9.3)," Journal of Heredity, vol. 86, pp. 485-486, 2002.

[14] S. Wright, "The interpretation of population structure by Fstatistics with special regards to systems of mating," Evolution, vol. 19, pp. 395-420, 1965.

[15] F. Rousset, Genepop 4.1 for Windows/Linux/Mac OS X, 2008.

[16] B. Rannala and J. L. Mountain, "Detecting immigration by using multilocus genotypes," Proceedings of the National Academy of Sciences of the United States of America, vol. 94, no. 17, pp. 9197-9201, 1997.

[17] S. Piry, A. Alapetite, J. M. Cornuet, D. Paetkau, L. Baudouin, and A. Estoup, "GeneClass 2: a software for genetic assignment and first-generation migrant detection," Journal of Heredity, vol. 95, no. 6, pp. 536-539, 2004.

[18] D. C. Quelle and K. F. Goodnight, "Estimating relatedness using genetic markers," Evolution, vol. 43, no. 2, pp. 258-275, 1989.

[19] GraphPad InStat version 5.04 for Windows, GraphPad Software, La Jolla California USA, http://www.graphpad.com .

[20] R. Valles-Jiménez, P. Cruz, and R. Pérez-Enriquez, "Population genetic structure of Pacific white shrimp (Litopenaeus vannamei) from Mexico to Panama: microsatellite DNA variation," Marine Biotechnology, vol. 6, no. 5, pp. 475-484, 2005.

[21] P. Cruz, A. M. Ibarra, H. Mejia-Ruiz, P. M. Gaffney, and R. Pérez-Enríquez, "Genetic variability assessed by microsatellites in a breeding program of pacific white shrimp (Litopenaeus vannamei)," Marine Biotechnology, vol. 6, no. 2, pp. 157164, 2004.

[22] R. Pérez-Enríquez, F. Hernández-Martínez, and P. Cruz, "Genetic diversity status of White shrimp Penaeus (Litopenaeus) vannamei broodstock in Mexico," Aquaculture, vol. 297, no. 1-4, pp. 44-50, 2009.

[23] N. Bierne, I. Beuzart, V. Vonau, F. Bonhomme, and E. Bedier, "Microsatellite-associated heterosis in hatchery-propagated stokcs of the srimp Penaeus stylirostris," Aquaculture, vol. 184, pp. 203-219, 2000.

[24] Z. Xu, J. H. Primavera, L. D. de la Pena et al., "Genetic diversity of white and cultured black tiguer shrimp (Penaeus monodon) in the Philippines using microsatellites," Aquaculture, vol. 199, pp. 13-40, 2001.

[25] E. Luvesuto, P. Dominguez de Freitas, and P. M. Galetti Junior, "Genetic variation in a closed line of the white shrimp Litopenaeus vannamei (Penaeidae)," Genetics and Molecular Biology, vol. 30, no. 4, pp. 1156-1160, 2007.

[26] J. A. H. Benzie, "Population genetic structure in penaeid prawns," Aquaculture Research, vol. 31, no. 1, pp. 95-119, 2000.

[27] G. Espinosa López, R. Díaz Fernández, U. Becker Zúñiga et al., "Population analysis of Cuban white shrimp Litopenaeus schmitti using allozymes as genetic markers," Revista de Investigaciones Marinas, vol. 24, no. 1, pp. 11-16, 2003 (Spanish).

[28] J. Soto-Hernández and J. M. Grijalva-Chon, "Genetic differentiation in hatchery strains and wild white shrimp Penaeus (Litopenaeus) vannamei (Boone, 1931) from northwest Mexico," Aquaculture International, vol. 12, no. 6, pp. 593-601, 2004.

[29] V. Sbordoni, E. de Matthaeis, M. Cobolli Sbordoni, G. La Rosa, and M. Mattoccia, "Bottleneck effects and the depression of 
genetic variability in hatchery stocks of Penaeus japonicus (Crustacea, Decapoda)," Aquaculture, vol. 57, no. 1-4, pp. 239251, 1986.

[30] Y. J. Borrell, J. Álvarez, E. Vázquez et al., "Applying microsatellites to the management of farmed turbot stocks (Scophthalmus maximus L.) in hatcheries," Aquaculture, vol. 241, no. 1-4, pp. 133-150, 2004.

[31] A. Artiles, M. Rubio, E. Gonzalez, R. Laria, and R. Silveira, "Crustacean virus of obligatory declaration by the OIE performance in cultured Litopenaeus vannamei in Cuba from 2003 to 2009," Ocean Docs Digital Repository, vol. 28, no. 1, pp. 12-18, 2011 (Spanish).

[32] R. Silveira-Coffigny, "Aquaculture health in Cuba," in Proceedings of the 1st Meeting of Interamerican OIE Comité for Aquatic Animals, Panama, Panama City, January 2006.

[33] S. Edmands, "Heterosis and outbreeding depression in interpopulation crosses spanning a wide range of divergence," Evolution, vol. 53, no. 6, pp. 1757-1768, 1999.

[34] M. Keller, J. Kollmann, and P. J. Edwards, "Genetic introgression from distant provenances reduces fitness in local weed populations," Journal of Applied Ecology, vol. 37, no. 4, pp. 647-659, 2000.

[35] S. Granier, C. Audet, and L. Bernatchez, "Heterosis and outbreeding depression between strains of young-of the-year brook trout (Salvelinus fontinalis)," Canadian Journal of Zoology, vol. 89, pp. 190-198, 2011. 

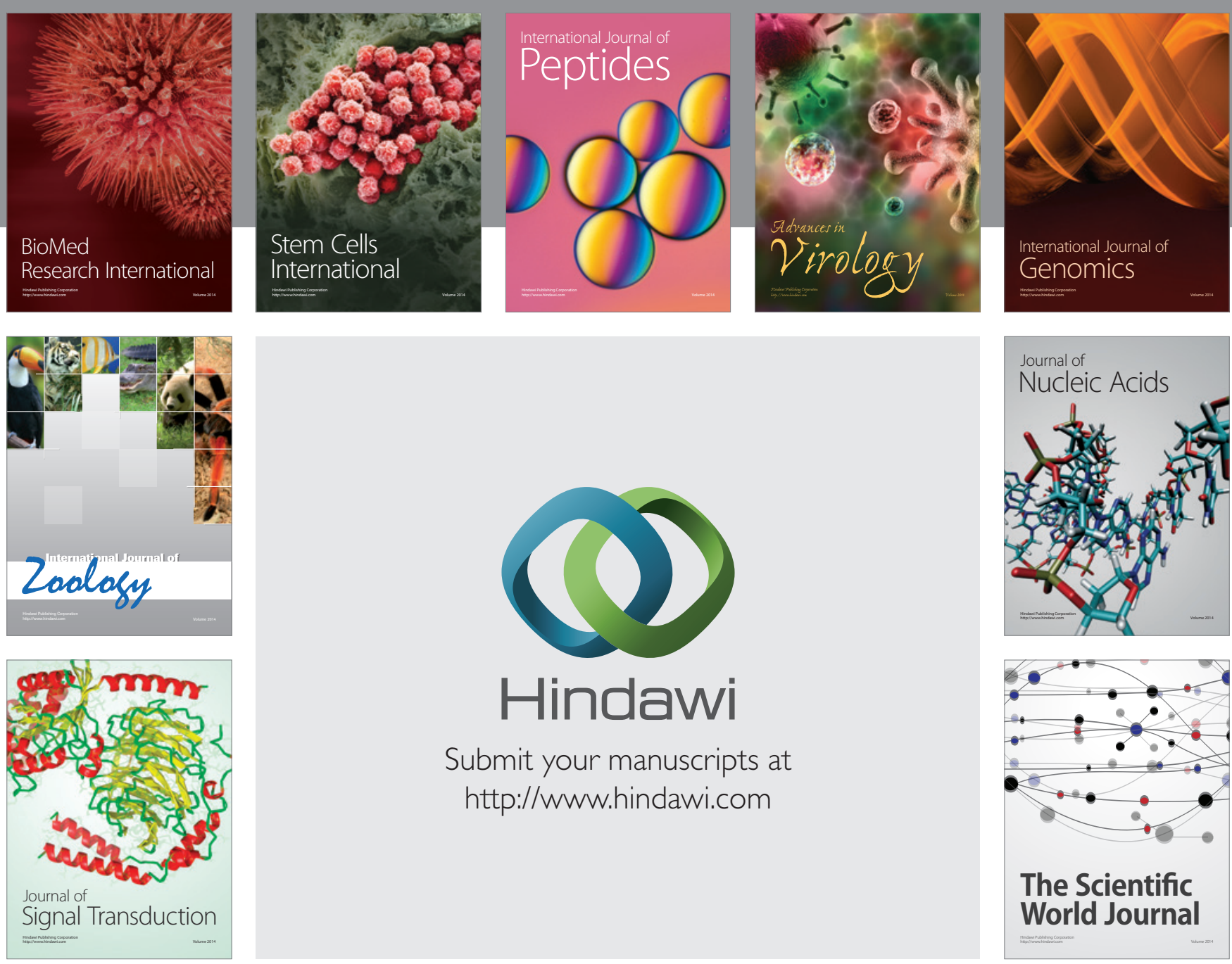

Submit your manuscripts at

http://www.hindawi.com
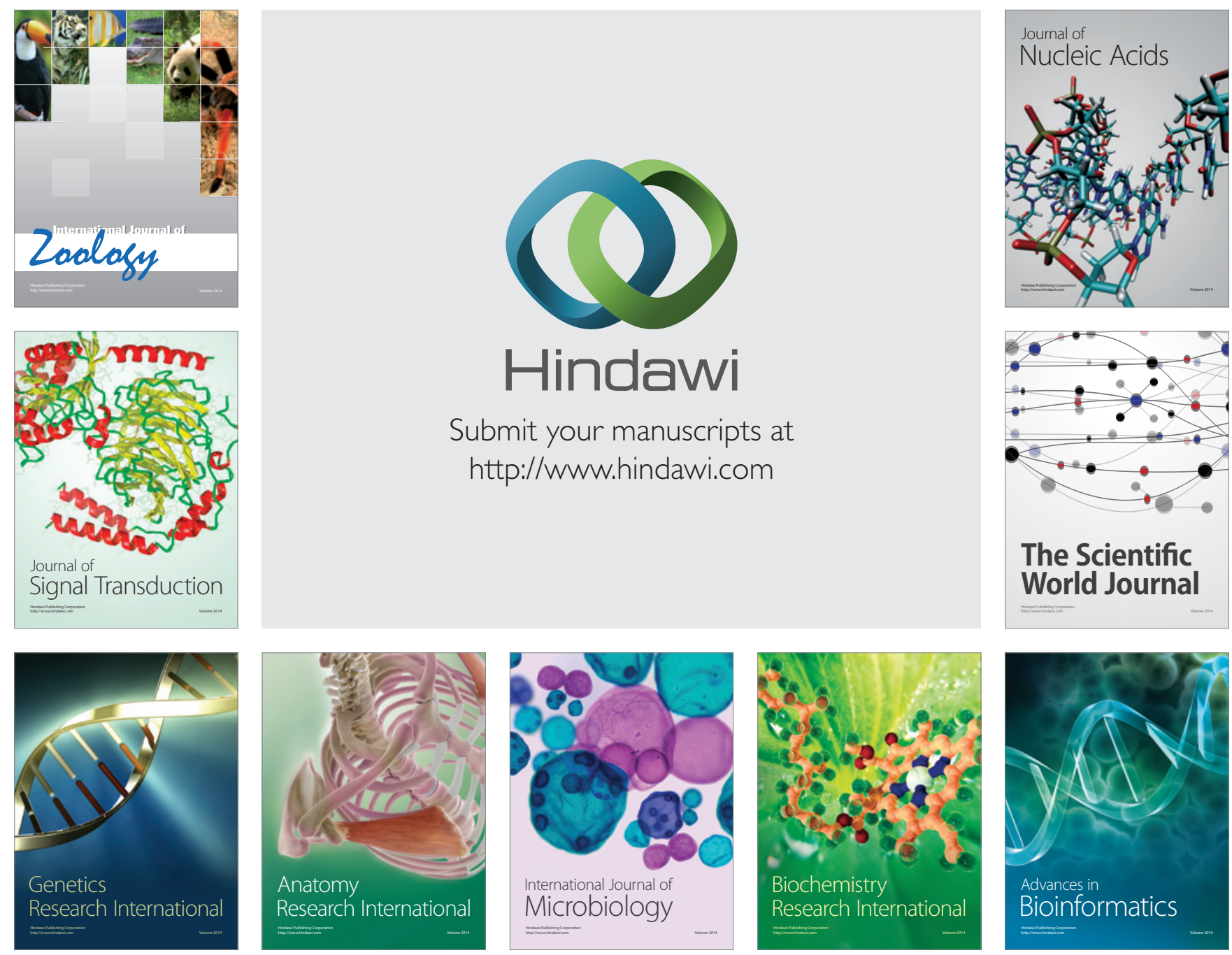

The Scientific World Journal
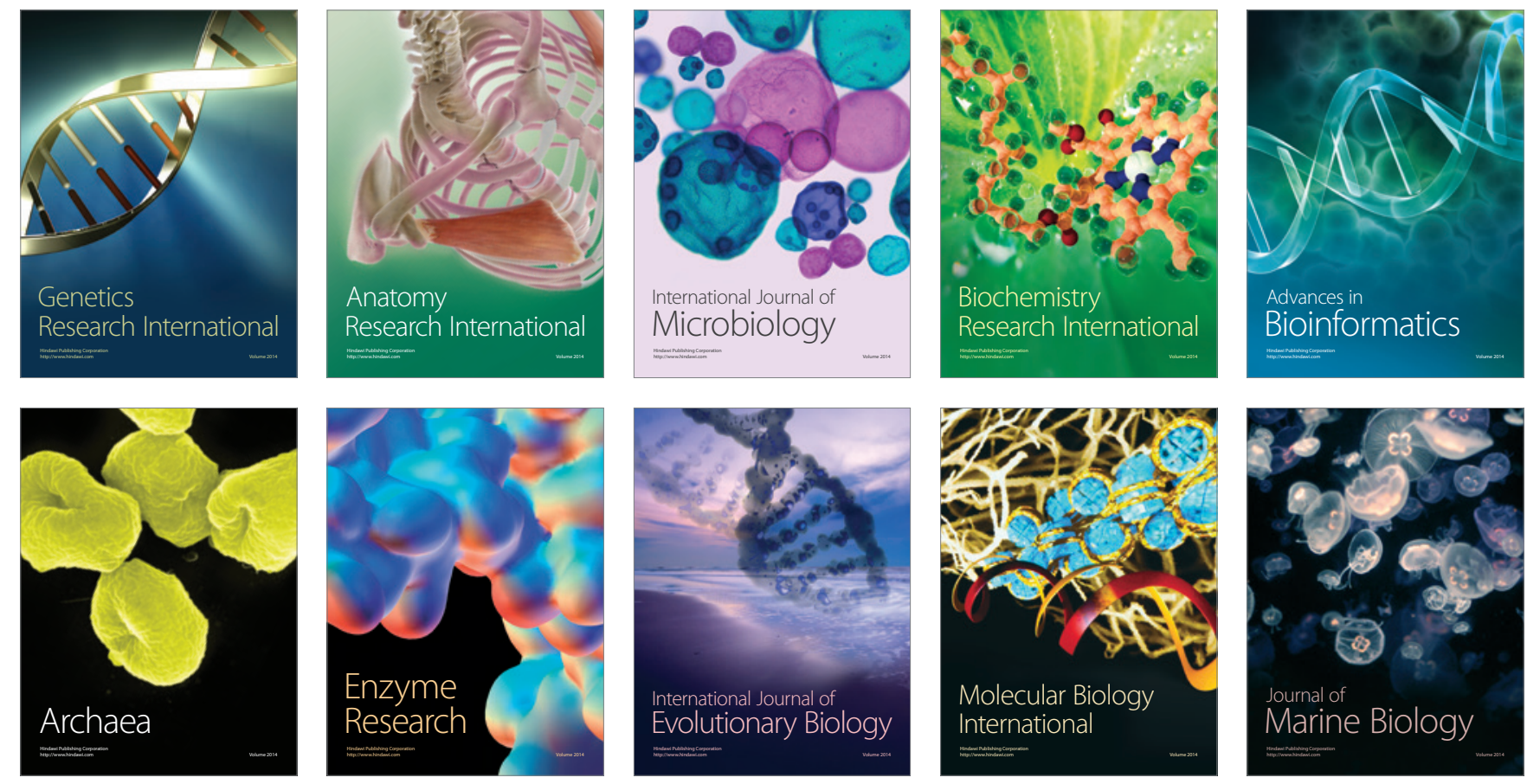